Agro-Science Journal of Tropical Agriculture, Food, Environment and Extension Volume 20 Number 3 (July 2021) pp. 91 - 98

\title{
ISSN 1119-7455 \\ EFFECT OF A COMMUNICATION PROGRAMME ON DIETARY BEHAVIOUR OF BENINESE FEMALE HANDBALL PLAYERS
}

\author{
"Kiki S.M., Bio-Nigan I., Tonon B.A., Gouthon G., Gouthon P. and Quenum C. \\ Sport, Health and Evaluation Research Unit (UR/SSE), \\ National Institute of Youth, Physical Education \& Sport (INJEPS), \\ University of Abomey-Calavi, Porto-Novo, Republic of Benin \\ *Corresponding author's email: sidoniekiki@gmail.com
}

\begin{abstract}
Dietary behaviour in humans is often influenced by intrinsic and extrinsic factors. During training camps, elite female handball players from different parts of the country are subjected to the same diet. The objective of the study was to determine the effect of a communication programme proposed in 2019, to the cadet and junior female handball players, on their dietary behaviour in Benin. This is an intervention study, with 36 cadet and junior female handball players selected to participate in the two training camps in 2019. Data on the physiological, social, cultural and psychological determinants of eating behaviour were collected through observation and questionnaire, as appropriate, before and after the intervention. Descriptive statistics were used to analyze the data and McNemar's test was used to analyze the contingency tables. Fifteen players significantly improved their eating behaviour from zero at baseline to good $(p=0.0001)$. The physiological, social, cultural and psychological determinants of eating behaviour were all improved at $p=0.0001$. The proposed communication programme induced a significant improvement in the eating behaviour of the handball female players studied. Nutrition education sessions and the integration of the players' food preferences into diets may have a more significant impact in a future study.
\end{abstract}

Key words: eating habits, handball, nutrition education, behaviour change communication, Benin

\section{INTRODUCTION}

Eating behaviour is defined as a set of simple habits, rules and norms constructed over time by individuals or social groups in relation to food (Etiévant et al., 2010; Olarewaju et al., 2020). It conveys social, mental and cultural representations that normally evolve over time, according to lifestyles (Ono et al., 2012). Because of its complexity, eating behaviour is not easy to change, but changes must be made when it tends to cause nutritionrelated diseases (WHO, 2018; Okugn and Woldeyohannes, 2018) which are also detrimental to sport performance (Joy et al., 2016). It is therefore necessary for athletes, who are an integral part of the society, to adopt good dietary behaviour throughout their careers, at home, during training camps and during competitions. In contexts, proposed diets must take into account the individual preferences of athletes and the characteristics of their family environment (Palomares, 2000).

The application of such diets would optimize the effects of the nutritional factors of sports performance (Sas-Nowosielskir and Wycislik, 2019), since during the regular phase of the sports season, female handball players, particularly those from Benin, live with their respective families and train in clubs only between 8 and $10 \mathrm{~h}$ per week (Gouthon et al., 2015; Nouatin et al., 2015; Linta et al., 2020). However, as competitions approach, these players from different social backgrounds are grouped together in two-week training camps (CE) and are subjected to intensive training of two sessions per day, followed by the same diet. The dynamics of the training camp group are thus likely to lead to a change in eating behaviour, i.e., the occurrence of new behaviours that may be favorable or harmful to the nutritional profile (Kelly and Barker, 2016). The same is true for the performance of female players (Nhantumbo et al., 2013), as long as diet is a determining factor in performance in sports (Cornil et al., 2020), particularly in handball, due to the high energy demand of match action (Saavedra, 2018).

Diversification of meals, as well as consuming them under healthy eating conditions recommended by official structures (Ejemot-Nwadiaro, 2015, Gacek, 2015), are therefore necessary to optimize their effects. For this reason, the eating behaviour of the players must be periodically evaluated to assess the gaps in terms of insufficiency and, if necessary, propose a strategy for adjustment or change. When considered, a communication-based intervention for changing the eating behaviour of athletes should have two objectives. The first objective is to contribute to the prevention of eating errors and eating disorders that are detrimental to the performance and health of athletes. The second objective is to rationalize eating patterns in order to sustain the positive changes achieved (Kenefick, 2018; Casa et al., 2019).

Please cite as: Kiki S.M., Bio-Nigan I., Tonon B.A., Gouthon G., Gouthon P. and Quenum C. (2021). Effect of a communication programme on dietary behaviour of Beninese female handball players. Agro-Science, 20 (3), 91-98. DOI: https://dx.doi.org/10.4314/as.v20i3.12 
A few authors have studied aspects such as the influence of commensality on diet (La Bounty et al., 2011) and meal frequency (Herman, 2017) in a disparate manner. At the African continental level and more specifically in Calanza, Mozambique, the study revealed that poor nutrition negatively influenced the sports performance of children aged 6 to 17 years (Nhantumbo et al., 2013). In Benin, work aimed at taking stock of the country's sports performance at different times since its independence in 1960 led to suggestions for improving sports management in the country and the physical capacities of athletes (Gouda and Kpazaï, 2012; Tonon et al., 2012; Gouthon et al., 2015; Nouatin et al., 2015; Linta et al., 2020). The behaviour of the female handball players who are the subject of the present study is identical to that of their nonsporting peers, when they live and eat in families, so that it is often difficult for them to adapt to the demands of meals during training camps. Therefore, an intervention is necessary to improve their level of adaptation and, consequently, their eating behaviour during training camps. That is why, this study was undertaken to measure the impact of a communication programme on the eating behavior of junior female handball players in Benin during training camps in preparation for the 2019 Continental Challenge Trophy.

\section{MATERIALS AND METHODS}

It was an uncontrolled intervention study, carried out with the female handball players of the Benin cadet and junior national selection, during two training camps of five days each, preparatory to the continental tournament of the Challenge Trophy of the year 2019. A first data collection on the players' eating behaviour was carried out during the five days of the first camp, as a diagnostic evaluation. During the last $24 \mathrm{~h}$ of the camp, the players attended the first session of the communication programme. After seven days of rest and just after their arrival at the second training camp, the players were again given the second session of the communication programme for another $24 \mathrm{~h}$, followed by the second collection of the same data during the five days of the new camp (Table 4).

Moreover, since it was difficult to separate the communication programme from the actions of the restorers and the Executive Committee of the Beninese Federation of Handball (BFH), sensitization and advocacy were carried out respectively towards these two actors, with a view to achieving results. Indeed, it was necessary to sensitize the restaurant owners by a communication on the respect of the execution of the proposed menu and then, the members of the Executive Committee of the Beninese Federation of Handball regarding the adequate financial contribution to better feed the players (Table 5).
The authorization of the Sectoral Scientific Committee of Sciences and Techniques of Physical, Sports and Socio-Educational Activities of the University of Abomey-Calavi was required. All the female handball players were informed of the objectives of the study before giving their free, informed and written consent to participate. They were assured that the results would be anonymously and confidentially used and that the interviews would be destroyed no later than 12 months after their use.

The study sample consisted of 17 cadets aged 13-16 years and 19 juniors aged 17-19 years giving a total of 36 female handball players, all members of the Republic of Benin national team. They were all selected to participate in the qualification tournament of the Challenge Trophy of Niamey in Niger Republic in 2019. Two survey techniques were used. These were direct observation of the eating behaviour of the female handball players, followed by a questionnaire survey. The direct observation technique was used to assess the physiological (except satiation), social and cultural determinants of the eating behaviour of the female handball players. The observation grid consisted of 61 items organized according to four dimensions. Apart from the socio-demographic data, the physiological determinant consisted of nine items, the social determinant consisted of 16 items and the cultural determinant consisted of 36 items.

The 10-item self-administered questionnaire was used to collect data on the psychological determinant with nine items, plus one aspect of the physiological determinant (the state of satiation) that were not directly observable. The sensitivity of the observation grid and questionnaire was assessed in a pre-test with 10 junior female handball players who were not part of the study sample. The two questions in the questionnaire, which were not clearly understandable, were reworded, before test. The content and structure of the tools were validated by the Human and Social Sciences expert researchers of magisterial rank from the University of Abomey-Calavi. The eating behaviour of the handball players was assessed through the four composite variables: physiological, social, cultural and psychological determinants.

The physiological determinant consisted of four sub-variables including the feeling of hunger, whether or not the meal was eaten, the state of satiation and the composition of the meal. The feeling of hunger was determined by the presence of the player in the dining hall at mealtime, while the consumption of meal was noted by the effectiveness of the eating act. The state of satiation was as provided by the players in their declaration. The composition of the meal was determined on the basis of the number of food groups present in the eight commonly selected groups of food (AFSSA, 2000), in addition to beverages. These are: 
cereals/legume/tubers, sugar/sugar products, raw or cooked vegetables, raw or cooked fruit, fish/meat/eggs, dairy/milk products, vegetable fats, and animal fats; a list of food groups excluding with water and sweetened beverages.

The social determinant included commensality, timing, type, duration, frequency and structure of meals. These sub-variables were made operational in two or three modalities as appropriate. Commensality was reflected in the consumption of meals alone or in groups, meal schedules could be fixed or not, and the type of meal was classified as local, western or mixed. The meal was said to be local when it had been prepared using locally sourced foods traditionally. It was considered western when it was made with western foods and then prepared in a western (non-African) manner. It was mixed when it presented one or the other aspect of a local and western meal. The length of the meal indicated the time spent eating it. Meal frequency could vary from one to three (breakfast and/or lunch and/or dinner). The structure of the meals was assessed based on the number of dishes in each meal. It could vary from one to three, including a single course, two, or three courses (starter, main course and/or dessert). The cultural determinant included the following four aspects: food prohibitions, the posture adopted during the meal, the use or not of cutlery and the respect of hygiene rules during the eating act (washing hands before and after the meal, means of washing, drying hands and means of drying). The psychological determinant brought together three aspects: the presentation of the meal (color, arrangement or layout of the food in the tray), the aroma and then the taste of the meals.

Eating behaviour was considered as a composite dichotomous variable, i.e., with two modalities, Good or Bad. It was made up of four sub-variables or dimensions, namely the psychological, social, cultural and psychological determinants of eating behaviour. In order for a player's eating behaviour to be considered Good, all four determinants had to be assessed as Good. Each determinant was assessed as good in a player if at least $80 \%$ of the items comprising it were satisfactory.

All data from direct observation and the questionnaire survey were processed using SPSS software (IBM, USA, version 22.0). The number of staff by modality (good or bad) was inserted in the contingency table and only those who underwent a change as a result of the intervention itself were considered. This approach was implemented first for dietary behaviour and then for all four determinants of dietary behaviour. Afterwards, McNemar's test was conducted using the discordant values, i.e., those that showed changes at the end of the intervention. The significance level of the statistical tests was set at $p<0.05$.

\section{RESULTS \\ Socio-Demographic, Anthropometric and Sport Practice Characteristics of the Players}

The female handball players studied had an average age of $17.0 \pm 1.6$ years, an average body weight of $59.2 \pm 6.4 \mathrm{~kg}$ and an average height of $162.8 \pm 0.7 \mathrm{~cm}$. Among them, 17 (42.2\%) were under 17 years of age. Four of the players had elementary school education, while the rest of the group had at least secondary school education. The female handball players came from the three regions of the country: northern, central, and southern Benin. Of the 36 female handball players, $12(33.3 \%)$ were in their first national selection (Table 1). There was no significant difference in data processing between those under 17 years of age (cadets) and those between 17 and 20 years of age (juniors). For this reason, the results were confounded for the two categories.

\section{Changes in Eating Behaviour}

Prior to the communication programme, all the 36 female handball players studied had poor eating behaviour (Table 2). At the end of the programme, 15 or $41.7 \%$ of the participants, had good behaviour, the difference being significant at $p=0.0001$.

\section{Changes in the Determinants of Eating Behaviour Observational data: physiological, social and cultural determinants}

At the end of the first training camp (Table 3), the number of female handball players who performed well for the physiological determinant was 36 versus $8(p=0.0001)$ at the beginning, for the social determinant 36 versus $18(p=0.0001)$ and for the cultural determinant 9 versus $0(p=0.0001)$.

\section{Data from questionnaire survey: psychological determinant}

On psychological determinant (Table 4), the number of players with good behaviour improved by 8 to $15(p=0.0001)$ between the start and end of the communication programme.

Table 1: Socio-demographic, anthropometric and sport participation characteristics of the female handball players studied (number of players studied, $n=36$ )

\begin{tabular}{ll}
\hline Variables (units) & Mean \pm standard deviation \\
\hline Age (years) & $17.0 \pm 1.6$ \\
Size $(\mathrm{cm})$ & $162.9 \pm 7.2$ \\
Body mass $(\mathrm{kg})$ & $59.2 \pm 6.4$ \\
Body mass index $\left(\mathrm{kg} / \mathrm{m}^{2}\right)$ & $22.3 \pm 1.6$ \\
Daily hourly training mass $(\mathrm{H})$ & $5.0 \pm 0.0$ \\
Seniority in practice (years) & $1.7 \pm 0.6$ \\
\hline
\end{tabular}

Table 2: Changes in eating behaviour induced by the communication programme in the female handball players studied ( number of players studied, $n=36$ )

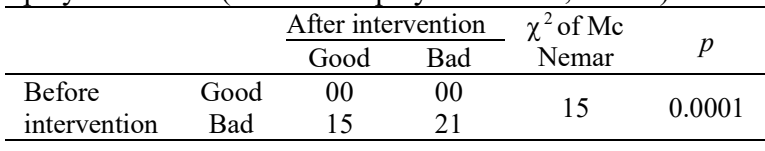


Table 3: Changes in the determinants of dietary behaviour induced by the communication programme for the female handball players studied (number of players studied, $n=36$ )

\begin{tabular}{|c|c|c|c|c|c|c|}
\hline & \multirow{2}{*}{ Déterminants } & & \multicolumn{2}{|c|}{ Measures 2} & \multirow{2}{*}{$\begin{array}{c}\chi^{2} \text { of } \\
\text { McNemar }\end{array}$} & \multirow[b]{2}{*}{$p$} \\
\hline & & & Good & $\mathrm{Bad}$ & & \\
\hline \multirow{8}{*}{ Measures 1} & \multirow{2}{*}{ Physiological } & Good & 08 & 00 & \multirow{2}{*}{28} & \multirow{2}{*}{0.0001} \\
\hline & & $\mathrm{Bad}$ & 28 & 00 & & \\
\hline & \multirow{2}{*}{ Social } & Good & 18 & 00 & \multirow{2}{*}{18} & \multirow[b]{2}{*}{0.0001} \\
\hline & & Bad & 18 & 00 & & \\
\hline & \multirow{2}{*}{ Cultural } & Good & 00 & 00 & \multirow{2}{*}{9} & \multirow{2}{*}{0.0001} \\
\hline & & Bad & 09 & 27 & & \\
\hline & \multirow{2}{*}{ Psychological } & Good & 08 & 00 & \multirow{2}{*}{7} & \multirow{2}{*}{0.0001} \\
\hline & & Bad & 07 & 21 & & \\
\hline
\end{tabular}

Measures 1: before the communication programme; Measures 2: after the communication programme;

Good: number of female players with good behaviour; Bad: number of female players with bad behaviour

Table 4: Female Handball Communication Programme adapted from the Prochaska and Di Clémente's (1983) Model

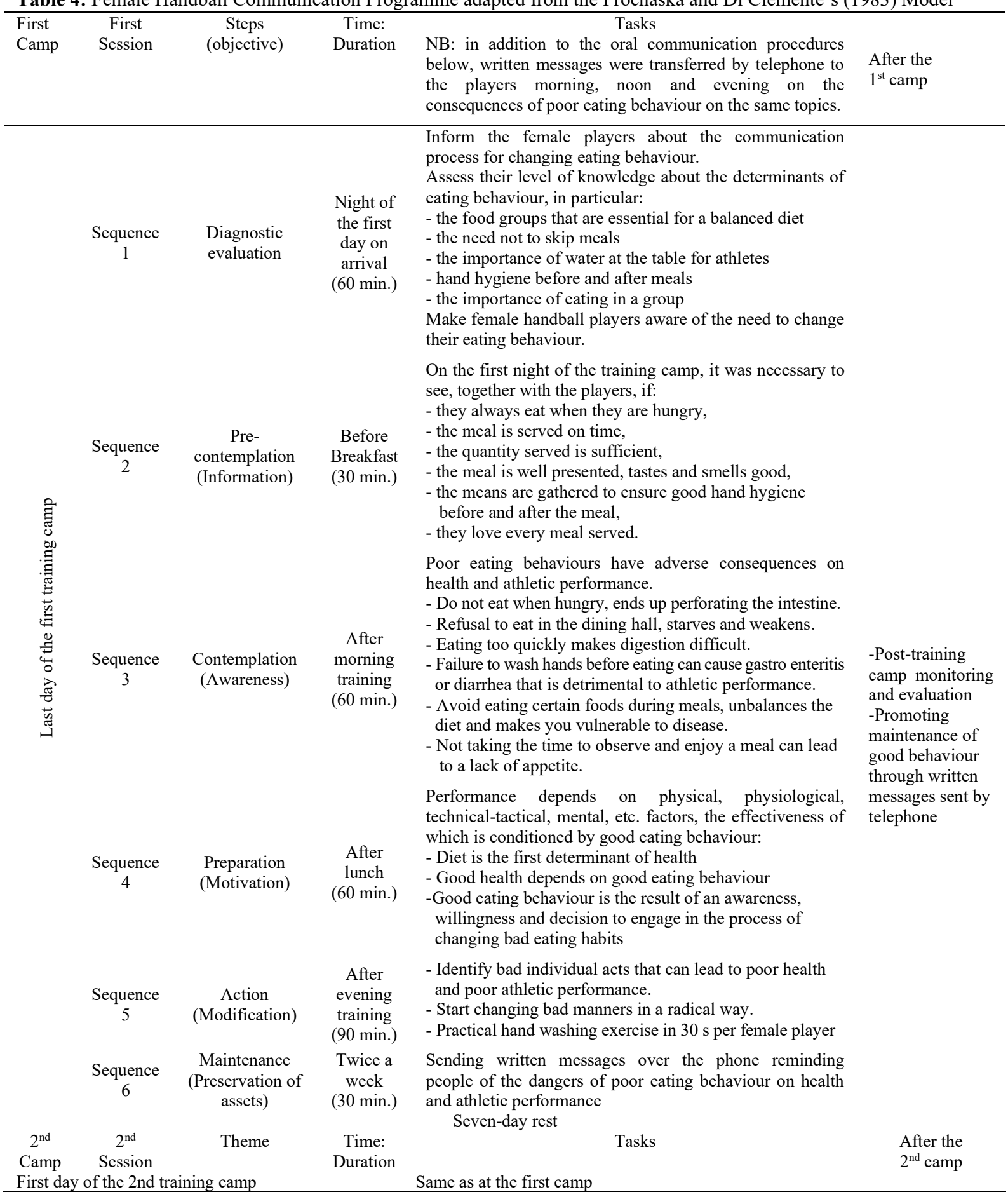


Table 5: Intervention content for restaurateurs and members of Beninise Federation of Handball (HFB)

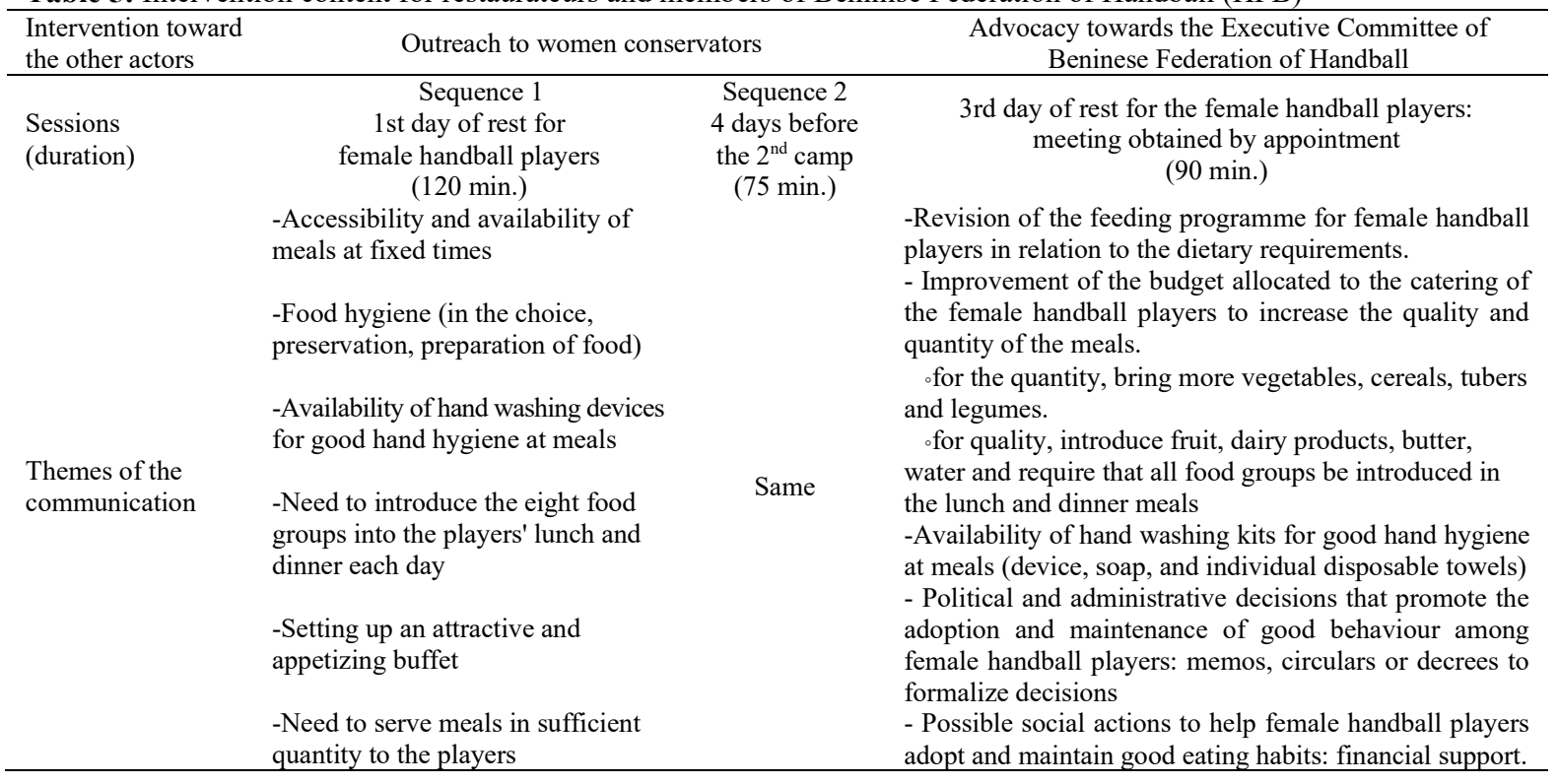

\section{DISCUSSION}

The objective of this study was to determine the effect of a communication programme on the dietary behaviour of Benin's elite cadet and junior female handball players during training camps in 2019. The results obtained from this study are reliable because they highlighted the actual dietary behaviour of the players under real conditions of intensive training in preparation for a continental competition. Considering the importance of the stake, the Handball Federation of Benin had implemented all the means to improve the performance of the players before the Challenge Trophy.

The selection of the handball players was done on the whole Beninese territory in order to respect a good representativeness. The players came from different regions and therefore had different cultures. This diversity of cultures could have been an asset in other situations but are limiting factors in preparation of a continental level competition. These limits are especially observable on food plan since the female handball players do not have habits and behaviours in relation to food. The regrouping was necessary to facilitate the cohesion of the selection, to ensure at least three meals per day to each of them because of the physical and physiological requirements of the trainings, to constitute a homogeneous group.

The Beninese selection met the international standards in terms of age (IHF, 2018). However, in terms of BMI, body mass and height, these anthropometric characteristics of the cadets were lower than those of their international counterparts, whose values were defined above theirs in a systematic review of 38 articles (MartínezRodríguez et al., 2020). This observed deficiency in the anthropometric characteristics of cadets could disadvantage them during competition.
In this clustering context, it would have been risky to create a control group that would not have benefited from the communication programme. This was why all the players participated in this programme aimed at improving their eating behaviour, with a view to contributing to the optimization of all the factors that could contribute to the team's good performance. Thus, all the athletes were followed by direct observation during the three daily meals served during the two training camps. The observation made it possible to determine the recurrences of the eating behaviour of the studied female handball players.

This study revealed that initially these female players generally had poor eating behaviour. This behaviour was strongly influenced by poor cultural and psychological determinants, through poor hand hygiene and lack of taste, as well as inadequate preintervention meals. Indeed, the female players did not systematically wash their hands before and after meals. They also did not wipe their hands dry after did washed them. This lack of hygiene could expose female handball players to the risk of nutrition-related communicable diseases (WHO and FAO, 2003), which can impair both their health and athletic performance (Nhantumbo et al., 2013).

Moreover, in African culture, including that of Benin, eating by hand is very common and is strongly associated with the hedonic nature of meals. Sometimes, even when using cutlery, the individual does not hesitate to plunge his hand into the plate to take a piece of meat that the fork cannot prick, because of the bone, and then, afterwards, licks the fingers. This situation was accentuated during the present study by the fact that the knives were not part of the cutlery made available to the players. As a result, many players experienced the need to use their fingers to grasp a piece of food at some point during the meal. It is therefore essential 
to wash their hands with soap and water before sitting down to eat, whether or not they have cutlery (Ejemot-Nwadiaro et al., 2015). The poor hand hygiene practice observed among most elite female handball players in Benin before the intervention may be partly the result of inadequate hand washing facilities (only one facility for all the 36 players before and after meals) and the lack of soap. This result is similar to that found in the general population, particularly among members of households surveyed in Abobo District in Ethiopia, where $49 \%$ of the subjects studied had poor food hygiene practices associated with poor hand washing device (Okugn and Woldeyohannes, 2018).

The psychological determinant is an important aspect of female handballers' eating behaviour, as it facilitates consumption of food by activating the appetite through the quality of presentation, aroma, and taste of food (Menzel et al., 2019). The psychological determinant highlights the role of the sensory properties (visual and olfactory) of food in the modulation of behaviour before consumption or palatability during the eating act (Nicklaus and Boumez, 2016). A meal that is not well presented or does not have an appetizing aroma, even if it is succulent, may not attract the consumer. In Nigeria, preference for rice consumption is a function of taste and quality among other factors (Nwachukwu and Achike, 2020). Thus, at the first training camp, according to the players, the meals were generally not well presented and were not sufficient. Being subjected to a unique diet with no other alternative, they therefore felt the need to eat despite their reluctance, with insufficient food being served to meet their energy needs. These results therefore require intervention to assess the changes.

The intervention programme, based on awareness sessions, improved the physiological and social determinants in all players. At the second training camp, after the intervention, the players reported having eaten their fill with appetite. This can be explained by the significant improvement in the hedonic aspect of meals, i.e. taste, aroma and presentation. This change was itself favored by the improvement in the composition of the meals and an increase in their quantity obtained through the sensitization of the restaurateurs and advocacy with the BHF. It was indeed difficult to separate the communication programme aimed at improving the behaviour of female handball players from the sensitization of the restaurant owners who were responsible for the meals consumed by the players and advocacy with the BHF which is responsible for financing and organizing these training camps. All these interventions had borne fruit because, at the first camp, the female handball players were generally served only one main course, without water to drink at the table. In the second camp, on the other hand, they were served at least one main course (main dish), a dessert (raw fruit) and water at each main meal, i.e., lunch and dinner.
After the intervention, significant good eating behaviour was observed in nearly half of the female handball players, due to the culinary improvements. This change obtained over a 12-day period from the end of the first camp to the end of the second, made it possible to say that a repetition of such communication programme could have greater positive effects for the players, if a decision were made to do so. However, the lack of availability of the players did not allow an intervention longer than the $48 \mathrm{~h}$ that was stipulated in the research protocol. It is hoped that the good behaviour observed in the 15 gamblers will continue in their families and in their daily lives. It is also desirable that their good behaviour influence that of their peers and their entire immediate environment.

For a sustainable change in eating behaviour in female handball players, it is recommended that the different determinants studied be taken into account through family, school and social education. If the right gestures and behaviours are adopted systematically and regularly within the family, the players will be able to apply them effortlessly everywhere, even in training camps, since it has been proven that their age $(17.0 \pm 1.6$ years $)$ is strongly associated with the formation of their identity (Abd El-Shaheed et al., 2019). School education also has a fundamental role to play, as rules of hygiene and good conduct must be also taught at school. However, there is no official school food policy regulated by authorities in charge of education (Nago et al., 2012). Thus, the time devoted to this training in school is insufficient (less than 120 minutes per week) to have a significant impact on students' behaviour.

The suggestion made here is to increase the amount of time devoted to this topic in schools, based on the idea that the school environment contributes to building good eating behaviour over time (Costa et al., 2010). Trainers/teachers should also devote time to coaching athletes on different aspects of the determinants of eating behaviour. This will ensure that good eating behaviours are sustained over time for players, whether they are in the school, family or sport environment. It is therefore essential to train the trainers in the adoption of good eating behaviour in order to influence the athletes in their way of doing things.

\section{CONCLUSION}

The hypothesis of the study was that a communication programme could have a positive effect on the eating behaviour of Benin's national elite female cadet and junior handball players during training camps in preparation for the 2019 continental Challenge Trophy tournament. Prior to the communication programme, all the female handball players studied had poor eating behaviour. After the communication programme, almost half of the players were able to improve their eating 
behaviour which became good. The proposed communication programme thus had a positive effect on the female players' eating behaviour. Therefore, the initial hypothesis was confirmed. The objective was also partially achieved, since more than half of the gamblers still had poor eating behaviour. The study highlighted the need to broaden the scope of intervention to all categories of handball players from Benin's national elite. The five aspects that significantly influenced the eating behaviour of the female handball players during the experimental training camps were presentation, aroma, taste of meals (psychological aspect), state of satiation (physiological aspect) and respect of hygiene rules during meals (cultural aspect). Therefore, it is necessary that other studies look at longer programme duration, while emphasizing these aspects identified as favorable to the adoption of good eating behaviour to obtain a better result. In the same way, it is imperative to sensitize the leaders of the Executive Committee of the Beninese Federation of Handball to facilitate the provision of teams, specialists in nutrition and dietetics of the sportsman, then adequate means to meet the dietary requirements of the elite female handball players. It is also desirable that a training or capacity building programme be developed for the members of the technical coaching staff to raise their level of knowledge on sports nutrition. This acquired ability will allow them to easily advise players in the area of nutrition. In light of these findings, it will be essential to conduct a study to better identify and understand the qualitative data collected during this survey.

\section{REFERENCES}

Abd El-Shaheed A., Mahfouz N., Moustafa R. and Elabd M. (2019). Alarming eating behaviours among adolescents in Egypt. Open Access Maced. J. Med. $\begin{array}{llll}\text { Sci., } & 7 & \text { (13), } & \text { 2189-2193. }\end{array}$ 10.3889/oamjms.2019.583

AFSSA (2000). Apports nutritionnels conseillés pour les sportifs. Synthèse des recommandations de l'AFSSA, CNERNA-NRS. Agence Française de Sécurité Sanitaire des Aliments (AFSSA). Maisons-Alford. URL: https://blog.nutridays.fr/wp-content/uploads/ doc-recommandations_alimentaires-sro-sportif.pdf

Casa D.J., Cheuvront S.N., Galloway S.D. and Shireffs S.M. (2019). Fluids needs for training, competition, and recovery in track-and-field athletes. Int. J. Sport Nutr. Exerc. Metab., 29 (2), 175-180. DOI: 10.1123/ijsnem.2018-0374

Cornil Y., Gomez P. and Vasiljevic D. (2020). Food as fuel: Performance goals increase consumption of high-calorie foods at the expense of good nutrition. $J$. Consum. Res., 47 (2), 147-166. DOI: 101093/jcr/ucaao12

Costa H.S., Vasilopoulou E., Trichopoulou A. and Finglas P. (2010). New nutritional data on traditional foods for European food composition databases. Europ. J. Clin. Nutr., 64 (3), S73-S81. DOI: 10.1038/ ejcn.2010.215default/files/2019-05/0_Regulations\%20F
Ejemot-Nwadiaro R.I., Ehiri J.E., Arikpo D., Meremikwu M.M. and Critchley J.A. (2015). Hand washing promotion for preventing diarrhoea. Cochrane Database Syst. Rev., 1 (9), 1-81. DOI: 10.1002/14651858.CD004265.pub3

Etiévant P., Bellisle F., Dallongeville J., Etilé F., Guichard E. et al. (2010). Les comportements alimentaires. Quels en sont les déterminants? Quelles actions, pour quels effets? https://hal.archivesouvertes.fr/hal-02182262

Gacek M. (2015). Association between self-efficacy and dietary behaviours of American football players in the Polish Clubs in the light of dietary recommendations for athletes. Rocz. Panstw. Zakl. Hig., 6 (4), 361-366. DOI: 10.1002/ ajhb.22403

Gouda S. and Kpazaï G. (2012). Le développement du sport de performance au Bénin: De l'analyse d'un modèle à un essai de problématique globale. Conseil pour le développement de la recherche en Sciences Sociales en Afrique, Afrique et développement., 37, 97-118

Gouthon P., Nouatin B.K., Messan F., Adido C., Tonon B.A. et al. (2015). Repeated-sprint ability and its correlates among handball players in Porto-Novo, Republic of Benin. Gazz. Med. Ital., 174 (11), 491498. URL: https//www.minervamedia.it/en/journals/ gazzetta-medica-italiana/article. php? $\operatorname{Cod}=\mathrm{R} 22 \mathrm{Y}$ 2015N11A0491

Herman P. (2017). The social facilitation of eating or the facilitation of social eating? J. Eat. Discord., 5, 16. DOI: $10.1186 / \mathrm{s} 40337-017-0146-2$

IHF (2018). Règlement pour les compétitions de la l'IHF, chap V. Fédération Internationale de Handball. URL: https://www.ihf.info/ sites/

Joy E., Kussman A. and Nattiv A. (2016). Update on eating disorders in athletes: A comprehensive narrative review with a focus on clinical assessment and management. Brit. J. Sports Med., 50 (3), 154162. DOI: $10.1136 /$ bjsports-2015-095735

Kelly M.P. and Barker M. (2016). Why is changing health-related behaviour so difficult? Public Health., 136, 109-116. DOI: 10.1016/j.puhe.2016.03.030

Kenefick R.W. (2018). Drinking strategies: Planned drinking versus drinking to thirst. Sport Med., 48 (1), S31-S37. DOI: 10.1007/s40279-017-0844-6

La Bounty P.M., Campbell B.I., Jacob W., Elfego G., John B. et al. (2011). International society of sports nutrition position stand: Meal frequency. J. Int. Soc. Sport Nutr., 8 (4), 1-4. DOI: 10.1186/1550-2783-8-4

Linta L.S.O., Gouthon P., Hountohotègbé T., Messan F., Nouatin B.K. et al. (2020). Réponses inflammatoires au cours d'une série de matchs chez des handballeurs de l'élite en République du Bénin. Int. J. Biol. Chem. Sci., 14 (4), 1354-1366. DOI: 10.4314/ijbcs.v14i4.15

Martinez-Rodriguez A., Martinez-Olcina M., HernandezGarcia M., Rubio-Aria J.A., Sánchez-Sánche J. et al. (2020). Body composition characteristics of handball players: Systematic review. Arch. Med. Deporte., 37 (1), 52-61. URL: https://www.researchgate.net/ publication/342551526

Menzel J.E., Reilly E.E., Lu T.J. and Kaye M.D. (2019). Conceptualizing the role of disgust in avoidant/restrictive food intake disorder: Implications for the etiology and treatment of selective eating. Int. J. Eat. Disord., 52 (4), 462-465. DOI: 10.1002/eat.23006 
Nago E.S., Verstraeten R., Lachat C.K., Dossa R.A. and Kolsteren P.W. (2012). Food safety is a key determinant of fruit and vegetable consumption in urban Beninese adolescents. J. Nutr. Edu. Behav., 44 (6), 548-555. DOI: 10.1016/j.jneb.2011.06.006

Nhantumbo L., Riberio J.A., do Santos F.K., Jani I.V., Gudo E.S. et al. (2013). Nutritional status and its association with physical fitness, physical activity and parasitological indicators in youths from rural Mozambique. Amer. J. Hum. Biol., 25 (4), 516-523. DOI: 10.1002 / ajhb. 22403

Nicklaus S. and Bourne M. (2016). Facteurs externes influençant le comportement alimentaire humain. Ann. $\quad$ Endocrinol., 77 (4), 241-247. https://doi.org/10.1016/j.ando.07.021

Nouatin B.K., Gouthon P., Amousou-Guénou D., Dansou P.H., Messan F. et al. (2015). Changes and recovery in fitness capacities following a series of handball matches played in the sub-tropical climate by division 1 amateur players. Biol. Exerc., 12 (2), 1-14. DOI: $10.4127 /$ jbe.2015.0089

Nwachukwu C.U. and Achike A.I. (2020). Determinants of consumption preference of local versus imported rice brands in Enugu State, Nigeria. Agro-Science, 19 (1), 31-36. DOI: https://dx.doi.org/10.4314/as.v19i1.5

Okugn A. and Woldeyohannes D. (2018). Food hygiene practices and its associated factors among model and non-model households in Abobo District, Southwestern Ethiopia: Comparative cross-sectional study. Plos One., 13 (4) e0194391. DOI: 10.1371/journal.phone.0194391

Olarewaju T.O., Orumwense L.A., Oke O.S., Idowu A.B. and Adeboye T.E. (2020). Assessment of knowledge on functional values of edible insects in peri urban communities of Ijebu Ode Local Government Area, Ogun State Nigeria. Agro-Science, 19 (4), 1-5. DOI: https://dx.doi.org/10.4314/as.v19i4.1
Ono M., Kenedy E., Reeves S. and Cronin L. (2012). Nutrition and culture in professional football: A mixed method-approach. Appetite., 58 (1), 98-104. DOI: $10.116 /$ j.appet.2011.10.007

Palomares E. (2000). Les cadres sociaux de l'identification culturelle: Une approche par l'alimentation à Cotonou. Bastidiana, 31-32, 208-223. https://halshs.archives-ouvertes.fr/halshs-01299171/ document

Prochaska J. and Di Clemente C. (1983). Stages and processes of self-change of smoking: Toward an integrative model of change. J. Consult. Clin. Psychol., 51 (3), 390-395. https://doi.org/10.1037/ 0022-006X.51.3.390

Saavedra J.M. (2018). Handball research: State of the art. J. Hum. Kinet., 63 (1), 5-8. DOI: 10.2478/hukin2018-0001

Sas-Nowosielskir Z. and Wycislik J. (2019). Apport énergétique et en macronutriments des grimpeurs sportifs polonais avancés. J. Phys. Educ. Sport, 19 (Suppl. 3), 829-832. DOI: 10.7752/jpes.2019.s3119

Tonon B., Agboton B., Falola J., Gouthon P., Nigan I., Ouendo E., Agboton H. and Poortmans J. (2012). Renal responses to a series of handball games played in Sub-saharan environment by amateur division 1 of female players. Adv. Phys. Edu., 2, 103-109. DOI: 10.4236/ape.2012.23019

WHO (2018). Global strategy on diet, physical activity and health: Thirteenth general programme of work, 2019-2023. World Health Organization, Geneva. URL: https://www.who.int/fr/news-room/fact-sheets /detail /healthy-diet

WHO/FAO (2003). Diet, nutrition and the prevention of chronic diseases. World Health Organization/Food and Agriculture Organization of the United Nations, Geneva.u URL: https// apps.who.int/iris/bitstream/ handle/10665/42665/WHO TRS916.pdf.jsessionid= 7213A07663929BFB62344C2FDF5B80?sequence $=1$ 